\title{
Cocriação de valor no transporte rodoviário de carga fracionada: um estudo de caso
}

\author{
Max Roberto da Silva $a^{\mathrm{a}}$, Igor Roberto Borges ${ }^{\mathrm{b}}$, Giancarlo Medeiros Pereira ${ }^{\mathrm{c} *}$, \\ Miriam Borchardt ${ }^{\mathrm{d}}$, Miguel Afonso Sellitto ${ }^{\mathrm{e}}$ \\ amaxrs@terra.com.br, Unisinos, Brasil \\ bigorroberto.borges@gmail.com, ULBRA-EaD/Unisinos, Brasil \\ c*gian@unisinos.br, Unisinos, Brasil \\ dmiriamb@unisinos.br, Unisinos, Brasil \\ esellitto@unisinos.br,Unisinos, Brasil
}

\section{Resumo}

Este artigo investiga se a cocriação de valor pode ser aplicada pelos prestadores de serviços de transporte. 0 estudo focalizou os transportadores e operadores logísticos. Um estudo de caso múltiplo foi realizado. Constructos afetos ao tema cocriação de valor foram extraídos da literatura para a consolidação da fundamentação teórica da pesquisa. Os seguintes tópicos foram investigados: demandas de valor dos compradores, critérios utilizados pelos compradores para avaliar o valor oferecido pelos prestadores de serviços e a possibilidade de cocriação de valor entre os compradores e vendedores. Os achados apontam duas principais barreiras para a cocriação de valor nos serviços de transporte, a saber: um grande número de prestadores de serviços (o que força os provedores de serviço a focalizar essencialmente a dimensão custo dos serviços) e as exigências dos clientes. A combinação dos referidos elementos sugere a impossibilidade de adoção de cocriação no contexto estudado. Esses resultados também podem indicar a existência de um limite inferior para a abordagem de valor no setor de serviços (por caso, nos serviços de transporte de carga).

Palavras-chave

Cocriação de valor. Serviços. Transportes. Valor.

\section{Introdução}

Transportadores rodoviários de carga fracionada são empresas que vendem, em uma mesma viagem, parcelas de sua capacidade de transporte para embarcadores de diferentes setores de atividades e/ ou operadores logísticos. Em países de dimensões continentais, tais como o Brasil, carente de outros modais, o transporte rodoviário de cargas é responsável por mais de 60\% dos bens transportados (Wanke, 2012). Serviços de transporte geralmente englobam operações de coleta de carga na origem, transferência a terminais ou facilidades intermediárias, consolidação e desconsolidação de cargas, classificação, distribuição local e entrega no destino final (Alamo \& Brinati, 2006).

Em nível mundial, as pesquisas na área de serviços de transporte de carga têm se concentrado na busca de métodos e alternativas que minimizem os custos de transporte. Temas, tais como análise de roteiros e melhorias operacionais diversas foram objeto de atenção de diversos autores (Özkaya et al., 2010; Lin et al., 2009; Smith et al., 2007; Yang et al., 2010; Han \& Yang, 2009). Um dos periódicos de reconhecida relevância científica que publicou os artigos citados foi o Transportation Research Part E: Logistics and Transportation Review.

Em adição à gestão com foco nos elementos geradores de custo, a literatura apresenta a alternativa da ampliação do valor entregue ao cliente como elemento de competição em serviços de transporte. A ampliação de valor oferecido ao cliente pode permitir que as prestadoras de serviço gerem novos negócios ou ampliem suas margens de ganho nos negócios 
atuais (Pereira et al., 2011). Dentre as linhas de investigação científica nessa área cite-se a "cocriação de valor", a qual se caracteriza pela atuação conjunta de fornecedores e clientes em projetos de melhoria de produtos ou serviços (Bolton \& Saxena-lyer, 2009; Hoyer et al., 2010). Cumpre destacar que o tema vem ganhando considerável espaço em importantes periódicos tradicionalmente focados na área de serviços, a saber: Journal of Service Research, Journal of Service Management, The Service Industries Journal e Industrial Marketing Management. Os trabalhos relatados nesses periódicos versam sobre os benefícios da cocriação para as organizações (Franke et al., 2009; Mathwick et al., 2007; Kristensson et al., 2004; Hoyer et al., 2010), suas implicações na equipe de trabalho, as estratégias para o envolvimento dos clientes no processo de cocriação de novos serviços baseados em tecnologia (Kristensson et al., 2008), os requisitos necessários para que um fornecedor de produtos se torne um provedor de soluções (Helander \& Möller, 2008), os desafios para a viabilização da CD - Customer-Dominant Logic ou Lógica de Dominação do Cliente (Heinonen et al., 2010) e a relação dos consumidores com as empresas em níveis de indutores e barreiras (Hoyer et al., 2010). Barry \& Terry (2008) identificaram ainda três momentos em que a interação de cocriação de valor pode ocorrer: antes da entrega (engenharia e consultoria), ao longo da entrega (instalação e treinamento) e após a entrega (manutenção e assistência técnica).

A análise dos referenciais listados sugere que a gestão dos serviços de transporte de cargas somente pode ser feita pela perspectiva da "redução de custos". Essa dedução advém do fato de que, até onde se pesquisou, a literatura científica não apresentou nenhum estudo focado na gestão com base no "valor agregado" pelo prestador desse tipo de serviço. Essa constatação deixa margem a dúvidas sobre a real possibilidade de gestão dessas empresas com base exclusivamente na abordagem do valor.

0 objetivo deste artigo é analisar a possibilidade de desenvolvimento de projetos de cocriação de valor nos serviços de transporte rodoviário de carga. A questão de pesquisa foi: "Como a cocriação de valor pode ser adotada nos serviços de transporte rodoviário de cargas?" Como hipótese de pesquisa, foi analisada a possibilidade de se administrarem empresas de transporte com base também em objetivos de gestão de valor e cocriação de valor. Para a investigação da hipótese, foram utilizadas variáveis baseadas em dimensões propostas na literatura Tsai et al., 2007 a saber: financeira, entregas, responsividade, informações e percepção geral do serviço. Nesse contexto, o presente artigo almeja colaborar para a ampliação do entendimento científico acerca das possibilidades de gestão das empresas de serviços de transportes de carga com base nos postulados do valor agregado. 0 método de pesquisa foi o estudo de caso exploratório múltiplo envolvendo alguns dos principais contratantes do transporte rodoviário de cargas, a saber: os embarcadores (geralmente indústrias) e os operadores logísticos (empresas que fazem a gestão de estoques, armazenagem e gestão de transportes). Os achados auferidos junto a esses clientes são confrontados com as informações fornecidas por um conjunto de transportadores. Segundo Yin (2003), questões do tipo "como" podem ser respondidas por estudos de caso. A investigação tomou por base constructos de cocriação de valor extraídos da literatura e foi desenvolvida no ano de 2010. A pesquisa inicialmente objetivou identificar os critérios considerados pelos embarcadores e operadores logísticos para avaliar a oferta de valor dos transportadores rodoviários independentes. Com base nessas, foram estão analisadas as alternativas para o desenvolvimento de projetos de cocriação entre os prestadores de serviços de transporte de cargas e seus contratantes. Os achados sugerem que a associação entre a grande oferta de serviços de transporte e as peculiaridades das demandas de valor apresentadas pelos seus clientes impede o desenvolvimento de projetos de cocriação de valor no setor.

0 artigo apresenta uma revisão da teoria sobre valor e cocriação de valor. Seguem-se metodologia da pesquisa, resultados e análise. Ao final apresentam-se conclusões. Até quanto foi pesquisado, não foram encontrados estudos de caso similares ao aqui realizado.

\section{Referencial teórico}

\subsection{Valor}

A entrega de um valor superior aos clientes se constitui no objetivo maior de todas as empresas de serviço na atualidade. Empresas percebidas como detentoras de um melhor desempenho na entrega de valor aos clientes conquistam importantes diferenciais ante seus concorrentes (Ulaga \& Chacour, 2001; Ulaga, 2003; Ulaga \& Eggert, 2006). Assim, a criação e a melhoria de ferramentas para a captura do valor em uso e sua posterior comunicação ao cliente se constituem em tópicos emergentes na área de serviços (Ostrom et al., 2010), a despeito de toda dificuldade inerente à identificação do valor percebido (Anderson \& Narus, 1998). Observa-se uma consonância de diversos autores no tocante à importância da criação de valor focada nas demandas e nos processos do cliente. Semelhante contexto ocorre na cocriação de valor, a qual é viabilizada mediante a ação conjunta do fornecedor e seu cliente (ex. Moller, 2006; Vargo 
\& Lusch, 2004, 2008). Moller (2006) observa que, até recentemente, a literatura acerca do valor percebido nada mencionava acerca da ação conjunta entre provedor e cliente empresarial. Contudo, recentemente Vargo \& Lusch (2004) propuseram a Lógica Dominante dos Serviços (SDL - Service Dominant Logic) a qual, juntamente com os trabalhos de outros autores (Payne et al., 2008; Prahalad \& Ramaswamy, 2004; Woodruff \& Flint, 2006) relembra aos gestores de serviços que o cliente é um cocriador do valor e não somente um mero consumidor dele.

0 conceito de valor agregado permite que provedores se concentrem na composição de ofertas de pacotes baseados em variáveis sob seu próprio controle (Woodruff \& Flint, 2006). Apesar da menção à percepção do valor em uso pelo cliente preconizado pela SDL (Vargo et al., 2008), a literatura ainda não apresenta uma definição consensual do termo, ou as formas de viabilizá-la (Macdonald et al., 2011). Assim, esse estudo adotará as definições utilizadas por Macdonald et al. (2011). A primeira dessas definições é a de valor em uso, que considera que ele se constitui em um resultado, propósito ou objetivo de cliente que foi viabilizado pelo serviço prestado. Essa definição se baseia em outros trabalhos de Vargo \& Lusch (2004, 2008) e Woodruff \& Flint (2006). Também com base em Vargo \& Lusch $(2004,2008)$, Macdonald et al. (2011) definiram serviço como o processo pelo qual o provedor atende às demandas do cliente. Para os propósitos deste trabalho, essa definição igualmente pareceu correta para os pesquisadores.

A literatura define solução nos serviços e transações entre empresas (B2B, ou business-to-business) como uma oferta individualizada desenvolvida para solucionar um problema complexo vivenciado pelo cliente e que efetivamente agrega valor ao mesmo (Evanschitzky et al., 2011). A noção de solução clarifica a necessidade de identificar-se o valor demandado pelo cliente segundo a perspectiva dele, em consonância com seus espaços e processos (Baines et al., 2007). Cumpre destacar que a identificação desse valor constitui o grande objetivo de $58 \%$ das empresas produtoras de bens dos Estados Unidos, haja vista que os serviços associados a esses produtos já respondem, hoje, por uma parcela considerável de seus ganhos líquidos (Neely, 2008). A mudança do foco de melhoria do produto para melhoria do par produto-serviço constitui-se, assim, numa ação estratégica também para as empresas de manufatura (Lindgreen \& Wynstra, 2005; Ngo \& 0’Cass, 2009).

\subsection{Cocriação de valor}

A co-criação de valor é um tema emergente nos meios acadêmicos e empresariais (Hoyer et al., 2010). A cocriação pressupõe que clientes e fornecedores trabalhem em conjunto com o objetivo de melhorar um produto ou serviço. Esse processo ocorre em vários contextos (Bolton \& Saxena-lyer, 2009) e constitui-se em um elemento essencial do SDL - Service-Dominant Logic ou Lógica Dominante dos Serviços (Lusch et al., 2007) e da manifestação de compromisso para com 0 cliente (Van Doorn et al., 2010). As ações de cocriação de valor geram produtos ou serviços que atendem melhor às necessidades do cliente, colaborando assim para a melhoria da sua satisfação, bem como lançando as bases para o seu engajamento em futuros projetos de melhoria (Hoyer et al., 2010). Contudo, Kristensson et al. (2008) alertam que o envolvimento do cliente aumenta o estresse em funcionários, podendo comprometer a satisfação do funcionário. Os referidos autores também apontam que os projetos de cocriação de valor precisam considerar aspectos culturais de ambas as partes.

A lógica CD (cliente-dominante) se opõe à lógica do provedor dominante (Heinonen et al., 2010). Segundo a lógica de CD, o valor dos serviços deve ser criado tendo em vista o valor em uso do cliente, o contexto de cada cliente e da experiência do cliente com relação ao serviço em questão. Os autores destacam os seguintes desafios para a viabilidade da lógica CD: o envolvimento da empresa, o controle do cliente sobre o processo de cocriação, a visibilidade da criação de valor, o escopo da experiência do cliente e as características da experiência do cliente.

Hoyer et al. (2010) analisaram os indutores e as barreiras à participação dos consumidores no processo, o impacto da cocriação em cada fase de desenvolvimento e os resultados dessa interação. Os achados desse estudo indicam que os aspectos econômicos, sociais, tecnológicos e psicológicos são indutores da participação do cliente na cocriação de valor, enquanto a redução de custos e a possibilidade de aumento dos benefícios percebidos pelo consumidor são os principais indutores da participação das empresas. Hoyer et al. (2010) também postulam que a preocupação com a confidencialidade, a partilha da propriedade intelectual, a sobrecarga de informação e a não viabilidade da solução desejada são elementos que podem restringir o interesse das empresas na cocriação.

Embora essa abordagem esteja se tornando mais conhecida (Vargo \& Lusch, 2004), alguns autores acreditam que falta uma base teórica sólida para fundamentar a compreensão das estratégias (por exemplo, antecedentes e processos críticos), que são necessários para o sucesso durante a cocriação de serviços (Kristensson et al., 2008). Outros acreditam que o estudo do assunto ainda está em fase inicial (Hoyer et al., 2010). 


\subsection{Avaliação dos serviços de transporte}

Com base em referências, Wen et al. (2011) propuseram um conjunto de indicadores destinados a avaliar o desempenho dos prestadores de serviços. Esses indicadores foram divididos nas seguintes dimensões: Financeira, Entregas, Responsividade, Informações e Percepção Geral. Na dimensão Financeira são avaliados aspectos como custos, descontos e resolução de inconsistências, com base no trabalho de Tsai et al. (2007). Na dimensão Entregas são considerados aspectos como velocidade (prazo de entrega), pontualidade e segurança da carga, também com base em Tsai et al. (2007), e freqüência de serviço, com base nas recomendações de Tsai et al. (2007), Hsu et al. (2005), Maier et al. (2002) e Norojono \& Young (2003). A dimensão Responsividade considera a resolução de problemas - abordada nos trabalhos de Aktas \& Ulengin (2005), Boyson et al. (1999), Menon et al. (1998) e Norojono \& Young (2003), a qual pode ser baseada no uso de meios tecnológicos (Rosa et al., 2006) -, a atitude dos colaboradores - investigada por Aktas \& Ulengin (2005) e Hsu et al. (2005) - e o gerenciamento de exceções proposto por Tsai et al. (2007). A dimensão Informações considera os trabalhos sobre rastreamento realizados por Aktas \& Ulengin (2005), Boyson et al. (1999), Hsu et al. (2005) e Lu (2004) e as soluções de informatização analisadas por Aktas \& Ulengin (2005), Boyson et al. (1999) e Lu (2004). Quanto a Percepção Geral, Wen et al. (2011) consideraram aspectos tais como capacidade financeira e conhecimento e postura, nos moldes do sugerido por Tsai et al. (2007).

\section{Metodologia}

\subsection{Projeto do estudo}

A investigação das possibilidades de desenvolvimento de projetos de cocriação de valor no setor de transportes rodoviários de carga fracionada tomou por base a metodologia de estudo de casos, de forma a colaborar para o entendimento científico da lacuna teórica apresentada. Adotou-se uma abordagem exploratória baseada na construção de uma teoria fundamentada, o que, segundo Yin (2003), se constitui na abordagem recomendada quando o objetivo é entender "como" e "por quê". 0 protocolo do estudo de caso usado neste trabalho inclui as seguintes seções: visão geral da investigação, tópicos, objetivos, coleta de dados e análises, nos moldes do prescrito na literatura (Yin, 2003).

0 método de trabalho foi: realização de entrevistas semiestruturadas baseadas em protocolo de pesquisa com ao menos dois executivos em nível de direção ou gerência de duas empresas embarcadoras, de duas operadoras logísticas, e de duas transportadoras; análise, validação e triangulação das respostas; e elaboração e organização dos achados de pesquisa.

Conforme Yin (2003), há quatro critérios para a avaliação da preparação de pesquisas empíricas, a saber: validade dos constructos, validade interna, validade externa e confiabilidade. Devido a possibilidade da baixa precisão dos métodos qualitativos advinda da riqueza de informação desses dados (Auerbach \& Silverstein, 2003), o presente estudo fez uso da análise de dados cruzados, de maneira a garantir a validade dos constructos do estudo.

A seleção das unidades de análise considerou dois grupos de empresas, a saber: as contratantes, composto por embarcadores e operadores logísticos; e os prestadores de serviços de transporte independentes. No grupo das contratantes, a seleção dos embarcadores considerou que eles deveriam ser indústrias de transformação que utilizam extensivamente o serviço de transportadores ou operadores logísticos para escoar sua produção. A seleção dos operadores logísticos foi feita a partir da lista dos principais provedores de serviços de carga. A Tabela 1 apresenta o perfil das empresas investigadas.

No grupo dos prestadores de serviços de transportes rodoviários de carga (contratados), a seleção considerou que eles deveriam, obrigatoriamente, operar com ambos os perfis de contratantes considerados. A aplicação dos referidos critérios levou à seleção das empresas apresentadas na Tabela 2:

Tabela 1. Perfil das contratantes investigadas.

\begin{tabular}{ll}
\hline \multicolumn{1}{c}{ Denominação } & \multicolumn{1}{c}{ Perfil } \\
\hline Embarcador A & Indústria de alimentos com portfólio de mais de 60 marcas, cerca de 1.200 funcionários, faturamento anual de \\
& $\mathrm{R} \$ 300$ milhões em 2010, com clientes em todo o território nacional e em outros 55 países. \\
Uma das maiores fabricantes de motocicletas do Brasil e do mundo, localizada na região Norte do país, local \\
onde trabalham aproximadamente 5 mil funcionários, que produzem ao redor de 25 mil motocicletas/mês. 0 \\
faturamento da empresa não foi divulgado. \\
Up dos cinco maiores operadores logísticos do mundo, presente em 220 países, com um faturamento anual em \\
torno de US\$ 46 bilhões. \\
Operador A
\end{tabular}


Buscando a confiabilidade dos dados foi realizada uma série de procedimentos ao longo da fase de design do estudo, coleta de dados e análise dos achados. $\mathrm{Na}$ fase de design foi definido um conjunto de variáveis destinadas a alinhar os achados de campo com a questão de pesquisa. Na fase de coleta foram realizadas entrevistas junto às empresas objeto do estudo, sendo elas posteriormente transcritas. Os achados transcritos foram enviados log,o após considerados prontos, aos entrevistados, para sua análise a aprovação (Yin, 2003). Conforme preconizado por Miles \& Huberman (1994) e Hill et al. (1997), dois pesquisadores coletaram os dados, de modo a aumentar o número de percepções convergentes (Eisenhardt, 1989).

A concepção do protocolo de investigação obedeceu aos referenciais norteadores do estudo: valor e cocriação de valor. Para a investigação deles foram utilizadas variáveis baseadas nas dimensões propostas por Tsai et al., 2007: Financeira, Entregas, Responsividade. Informações e Percepção Geral. A Tabela 3 apresenta o desdobramento dessas variáveis e as referências que subsidiaram a confecção do protocolo de investigação.

\subsection{Coleta de dados}

Nas diferentes unidades de análise investigadas, os entrevistados eram sempre profissionais em nível de direção e/ou gerência diretamente envolvidos com a operação dos serviços de transporte; tal prerrequisito tinha o intuito de viabilizar a coleta de informações confiáveis e válidas para os propósitos do estudo. Entrevistas semiestruturadas objetivaram conferir certo grau de liberdade aos entrevistados no desenvolvimento de suas ideias (Bryman, 2004). As entrevistas foram conduzidas entre setembro e dezembro de 2010, em reuniões que duraram de 60 minutos a 90 minutos. Para garantir maior liberdade aos entrevistados e, consequentemente, maior confiabilidade das informações prestadas, foi assegurado aos mesmos o anonimato, tanto deles quanto das empresas pesquisadas. As entrevistas foram finalizadas na medida em que os pesquisadores julgaram que nenhuma nova manifestação do entrevistado agregaria informações relevantes, nos moldes do sugerido pela literatura (Glaser \& Strauss, 2006; Strauss \& Corbin, 1990). As entrevistas foram mantidas flexíveis e o protocolo foi sempre modificado para refletir os conceitos e temas que emergiram espontaneamente, ou com o objetivo de melhorar a relação entre tempo e achados nas entrevistas realizadas (King, 2004).

\subsection{Análise dos achados}

Inicialmente procedeu-se à codificação dos achados por grupo de empresas entrevistadas. Posteriormente, os elementos codificados foram analisados individualmente, com o objetivo de identificarem-se padrões coerentes entre eles (Cassel \& Symon, 1990). Essa análise tomou por base as variáveis

Tabela 2. Perfil dos transportadores investigados.

\begin{tabular}{|c|c|}
\hline Transportador A & $\begin{array}{l}\text { Um dos três principais transportadores do país, atuante no segmento de carga fracionada e completa, com filiais } \\
\text { em todos os estados brasileiros, mais de } 2.500 \text { veículos, volume de cargas ao redor de } 600 \text { mil toneladas/ano e } \\
\text { faturamento anual superior a } R \$ 630 \text { milhões. }\end{array}$ \\
\hline Transportador B & $\begin{array}{l}\text { Empresa nacional atuante no segmento de cargas fracionadas e lotação, com mais de mil funcionários, faturamento } \\
\text { anual de aproximadamente R\$ } 84 \text { milhões e filiais nos estados do Rio Grande do Sul, Paraná, Santa Catarina, São } \\
\text { Paulo e Rio de Janeiro. }\end{array}$ \\
\hline
\end{tabular}

Tabela 3. Variáveis investigadas.

\begin{tabular}{lll}
\hline \multicolumn{1}{c}{ VARIÁVEIS } & \multicolumn{1}{c}{ ESPECIFICAÇÃo } & \multicolumn{1}{c}{ REFERÊNCIAS } \\
\hline Financeira & Custos, descontos e resolução de inconsistências & Tsai et al. (2007) \\
Entregas & Velocidade, pontualidade e segurança da carga & Tsai et al. (2007) \\
& Frequência do serviço & $\begin{array}{l}\text { Tsai et al. (2007); Hsu et al. (2005); Maier et al. (2002); e Norojono \& } \\
\text { Young (2003) }\end{array}$ \\
Responsividade & Resolução de problemas & Aktas \& Ulengin (2005); Boyson et al. (1999); Menon et al. (1998); e \\
& Atitude dos colaboradores & Norojono \& Young (2003)
\end{tabular}


descritas no protocolo de investigação e desvelou três elementos básicos afetos ao constructo Valor, a saber: Avaliação, Problemas e Encaminhamentos. No constructo Cocriação de Valor foram identificados os elementos Interesse e Possibilidades. A posterior codificação dos achados e a análise deles foram feitas conforme as prescrições de Yin (2003).

\section{Análise individual dos grupos}

A análise dos achados de campo junto aos diferentes grupos de empresas investigados (embarcadores, operadores logísticos e transportadores) é apresentada na sequência.

\subsection{Embarcadores}

No tocante aos critérios utilizados na avaliação dos prestadores de serviços, os embarcadores declararam avaliar seus fornecedores de transporte com base na pontualidade, flexibilidade, agilidade na solução de problemas e preço. Os embarcadores declararam que os provedores de serviços são substituídos em função do preço e/ou problemas de qualidade. Os entrevistados também declararam que os transportadores ajustam o nível de preço ao longo da relação, de formas a ampliar seus ganhos. Os embarcadores reconhecem que praticam a troca constante de provedores de serviço como forma de obter melhores preços.

Em se tratando de projetos de melhoria conjuntos, os entrevistados desse grupo declararam que a observação das metas de desempenho acordadas é a única coisa que um transportador precisa fazer para manter-se atrativo aos olhos dos embarcadores. Questionados sobre a existência de demandas ainda não atendidas pelos provedores de transporte, ou atendidas de forma parcial, os embarcadores reiteraram: "aos transportadores cumpre entregar a encomenda no prazo originalmente acordado e fornecer informação precisa acerca do estágio de andamento do serviço".

\subsection{Operadores logísticos}

Os operadores logísticos declararam avaliar os transportadores com base na pontualidade, acuracidade/agilidade das informações prestadas sobre o serviço em andamento, preço e prazo de pagamento. Aspectos como preço e/ou problemas de qualidade determinam a troca do provedor de serviços. Os operadores igualmente reclamaram da política do ajuste no nível de preços praticados pelos transportadores. Assim como os embarcadores, os operadores igualmente realizam comparações periódicas para reduzir custos e melhorar o preço que lhes é oferecido.
Os operadores logísticos declararam-se aptos a trabalhar em projetos de melhoria conjuntos. No entanto, entendem que os transportadores não estão habilitados a tal. Na visão desse grupo, cumpre ao transportador apenas cumprir os requisitos acordados. Aos transportadores, os operadores oferecem apenas a continuidade de sua relação negocial. Questionados sobre a existência de demandas ainda não atendidas pelos provedores de transporte, ou atendidas de forma parcial, os operadores citaram que suas demandas são simples, a saber: "entregas no prazo e informações precisas acerca do estágio de andamento do serviço”.

\subsection{Transportadores}

Os transportadores declararam que seus serviços são avaliados por embarcadores e operadores com base nos seguintes indicadores: preço, prazo de entrega no destino, pontualidade, integridade da carga (faltas e avarias), acuracidade e agilidade na informação. Queixaram-se da instabilidade gerada no mercado por embarcadores e operadores logísticos. Segundo os transportadores, muitos de seus clientes trocam de provedor por apenas algumas centenas de reais. Os transportadores destacaram a grande oferta de serviços de transporte verificada em seu negócio, oferta essa que força esses transportadores a permanentemente adequar o nível dos preços praticados de forma a ampliar, mesmo que levemente, seus ganhos. Os transportadores foram unânimes em afirmar que trabalham de forma reativa e não de maneira proativa, ou seja: na maioria das vezes somente reagem quando sabem que seus clientes estão cotando com terceiros. Com efeito, somente a iminente perda de algum cliente importante parece ser capaz de determinar uma revisão nessa política. A falta de comprometimento para com o transportador manifestada por embarcadores e operadores se constitui na grande preocupação dos entrevistados das empresas de transporte.

Os transportadores declararam que a grande oferta de provedores de serviços de transportes e o tipo de entendimento que os contratantes têm acerca do serviço transportes praticamente inviabilizam quaisquer ações de cocriação entre contratantes (embarcadores e operadores) e contratados (transportadores). Com efeito, todos os entrevistados declararam que a observação das metas de desempenho acordadas é a única coisa que um transportador precisa fazer para manter-se atrativo aos olhos de seus contratantes. Para enfatizar o contexto descrito, os transportadores mencionaram que os contratantes preferem incluir cláusulas de penalização ao transportador que atrase uma entrega em vez de interagirem com ele na busca conjunta de alternativas que sejam mutuamente 
benéficas. No que tange às demandas ainda não atendidas pelos provedores de transporte, ou atendidas de forma parcial, os transportadores confirmaram o pouco espaço para a cocriação de valor. Segundo eles, seu serviço virou uma espécie de commodity, assim, a ampliação da lucratividade de seu negócio restringe-se a ações focadas no rígido controle de todos os custos envolvidos no atendimento das demandas dos clientes, a saber: entrega no prazo, acuracidade, agilidade nas informações e baixo índice de faltas e avarias.

\subsection{Sintese da análise individual}

A análise individual dos grupos de casos revelou que os achados do constructo Valor poderiam ser categorizados em três grupos, a saber: avaliação do valor (doravante tratado como Avaliação), demanda não atendida (doravante tratado como Problemas) e encaminhamentos adotados pelas empresas em face dos problemas detectados (doravante tratado como Encaminhamentos). A Tabela 4 apresenta a síntese do constructo Valor conforme os grupos de empresas investigados.

No tocante ao constructo Cocriação de Valor, a síntese revelou dois elementos: Interesse e Possibilidades. A Tabela 5 apresenta os resultados da síntese do referido constructo conforme os grupos de empresas investigados.

\section{Análise entre os grupos}

A análise da demanda de valor entre os grupos dos embarcadores e dos operadores foi feita com base na sintese apresentada na Tabela 5 e revelou que os direcionadores de valor se restringem a aspectos tangíveis como preços, prazos, pontualidade, informações e isenção de danos à carga. Os achados indicam a possibilidade de que a grande oferta de provedores de serviços de transporte induz à competição por preços e não por valor agregado. Mesmo assim, os transportadores têm a necessidade de alterar preços em meio à relação, de forma a viabilizar ganhos financeiros mais aceitáveis. A variabilidade dos preços induz os embarcadores e operadores a periodicamente prospectar novos provedores de serviços que atendam às suas demandas de valor a um custo inferior. A associação entre as demandas de valor dos embarcadores/operadores e a grande oferta de provedores de serviço de transporte parecem ser elementos que restringem a cocriação de valor no transporte de cargas. Em decorrência dos elementos listados foi possível apurar-se que os entrevistados de todos os grupos de empresas não vislumbravam eventuais projetos passíveis de serem orquestrados conjuntamente (cocriação). A Tabela 6 apresenta os resultados da análise entre os grupos de casos pesquisados.

Tabela 4. Síntese do constructo Valor.

\begin{tabular}{|c|c|c|c|}
\hline ELEMENTOS & EMBARCADORES & OPERADORES & TRANSPORTADORES \\
\hline Avaliação & $\begin{array}{l}\text { Pontualidade, flexibilidade, agilidade } \\
\text { na solução de problemas e preço }\end{array}$ & $\begin{array}{l}\text { Pontualidade, acuracidade/agilidade } \\
\text { na informação, preço e prazo de } \\
\text { pagamento }\end{array}$ & $\begin{array}{l}\text { Preço, prazo de entrega no destino, } \\
\text { pontualidade, integridade da carga } \\
\text { (faltas e avarias), acuracidade e } \\
\text { agilidade na informação }\end{array}$ \\
\hline Problemas & $\begin{array}{l}\text { Alterações de desempenho ao longo } \\
\text { da relação }\end{array}$ & $\begin{array}{l}\text { Alterações de desempenho ao longo } \\
\text { da relação }\end{array}$ & $\begin{array}{l}\text { Falta de comprometimento por parte } \\
\text { dos contratantes }\end{array}$ \\
\hline Encaminhamentos & $\begin{array}{l}\text { Pesquisar novos provedores para } \\
\text { melhorar o serviço ou reduzir preços }\end{array}$ & ldem aos embarcadores & $\begin{array}{l}\text { Realizar melhorias apenas sob } \\
\text { pressão, de forma a manter o cliente }\end{array}$ \\
\hline
\end{tabular}

Tabela 5. Síntese do constructo Cocriação de Valor.

\begin{tabular}{llll}
\hline \multicolumn{1}{c}{ ELEMENTOS } & \multicolumn{1}{c}{ EMBARCADORES } & \multicolumn{1}{c}{ OPERADORES } & \multicolumn{1}{c}{ TRANSPORTADORES } \\
\hline Interesse & $\begin{array}{l}\text { Nenhum. A oferta de provedores } \\
\text { habilitados é grande. }\end{array}$ & $\begin{array}{l}\text { Operadores declararam-se aptos e } \\
\text { interessados. }\end{array}$ & $\begin{array}{l}\text { Grande enquanto estratégia de fidelização, } \\
\text { porém inviável em função da grande } \\
\text { concorrência verificada. }\end{array}$ \\
Possibilidades & $\begin{array}{l}\text { Nenhuma, pois aos transportadores } \\
\text { cumpre atender aos critérios } \\
\text { requeridos. }\end{array}$ & $\begin{array}{l}\text { Poucas, pois os transportadores não } \\
\text { estão habilitados. }\end{array}$ & $\begin{array}{l}\text { Nenhuma em função do caráter de } \\
\text { commodity. }\end{array}$ \\
\hline
\end{tabular}

Tabela 6. Síntese da análise entre os grupos.

\begin{tabular}{lll}
\hline \multicolumn{1}{c}{ ELEMENTOS } & \multicolumn{1}{c}{ VARIÁVEIS } & ANÁLISE \\
\hline VALOR & Avaliação & Preços, prazos, pontualidade, informações e isenção de danos à carga \\
& Problemas & Abundância de oferta induz à competição por preços e não por valor agregado. \\
& Encaminhamentos & Embarcadores e operadores periodicamente prospectam novos provedores de custo inferior. \\
COCRIAÇÃO DE VALOR & Interesse & A associação entre demandas de valor e abundância de oferta restringem a cocriação de \\
& valor no transporte de cargas. & Não se vislumbram projetos de cocriação. \\
\hline
\end{tabular}




\subsection{Triangulação das evidências}

A triangulação entre os achados das entrevistas, as observações dos pesquisadores em campo e os dados documentais referendam a análise entre os casos anteriormente apresentada, especialmente no que tange aos elementos Problemas e Encaminhamentos. Esse é o caso, por exemplo, das observações dos pesquisadores em campo, as quais indicaram uma grande oferta de serviços de transporte junto a postos de abastecimento de combustíveis próximos aos embarcadores e operadores pesquisados. Em muitos desses postos, veículos e motoristas independentes, ou de empresas transportadoras de diferentes portes aguardam pacientemente alguma proposta de frete (serviço).

Essa observação foi corroborada com a análise documental baseada no Boletim Estatístico da Confederação Nacional dos Transportes - CNT (2011), o qual registra mais de 150 mil transportadores registrados no país. Essa grande quantidade de transportadores, aliada à falta de regulamentação do mercado e à inexistência de maiores barreiras de entrada no setor fazem com que o setor de transportes seja de alta competitividade em termos de custo. 0 que também é corroborado por Wanke (2012), que afirma que os baixos fretes e o receio da ociosidade fazem com que transportadores aceitem operar em condições extremas, aumentando a oferta de serviços. A disponibilidade aumentada faz com que os fretes baixem ainda mais, realimentando o ciclo.

\section{Discussão}

Com base na síntese das análises dos grupos e entre os grupos, procedeu-se então à discussão dos achados ante o disposto na teoria. Essa discussão é apresentada na sequência, conforme os constructos Valor e Cocriação de Valor.

\subsection{Constructo Valor}

Conforme constatado, as demandas de valor afetas aos serviços de transporte de carga se restringem a aspectos tangíveis como preços, prazos, pontualidade, informações on-line e isenção de danos à carga. As referidas demandas parecem explicar o foco das investigações científicas descritas na teoria em nível global, a saber: melhoria do desempenho operacional e/ou redução dos diferentes custos incorridos na prestação de serviços de transporte (Özkaya et al., 2010; Lin et al., 2009; Smith et al., 2007; Yang et al., 2010; Han \& Yang, 2009).
A não observância das demandas de valor identificadas constitui a maior fonte de atritos entre contratantes e contratados. Com efeito, o pleno atendimento dessas demandas parece comprometer a lucratividade dos transportadores, razão pela qual eles alteram o nível de preços. Cumpre destacar que os próprios transportadores reconhecem o caráter reativo de sua postura. Para fazer frente a tal contexto, os embarcadores e os operadores periodicamente prospectam novos fornecedores no mercado.

\subsection{Constructo Cocriação de Valor}

Conforme identificado nas entrevistas, a combinação entre as demandas de valor e o grande número de transportadores induz à competição focada essencialmente em preço não em valor agregado. Essa condição restringe a execução de projetos conjuntos entre embarcadores/operadores e transportadores nos moldes do preconizado por Bolton \& Saxenalyer (2009). Nesse contexto, o que se observou nos casos analisados é um cenário totalmente diverso do postulado na literatura (Franke et al., 2009; Mathwick et al., 2007; Kristensson et al., 2004), especialmente no que tange às facilidades para a comercialização de serviços. Com efeito, os benefícios da cocriação postulados por Hoyer et al. (2010) são viabilizados mediante a identificação de novos provedores de serviço, ou então via o uso da prospecção desses provedores como forma de pressionar os transportadores que estão prestando serviços aos embarcadores e aos operadores.

A análise da triangulação apresentada, em conjunto com as conclusões anteriores, sugere que a grande oferta de prestadores de serviços de transporte de cargas constitui um importante fator limitador à execução de projetos de cocriação de valor. Com base nessa constatação, enuncia-se o seguinte achado de pesquisa, válido apenas no contexto das empresas investigadas: a grande oferta de prestadores de serviços se constitui importante fator limitador à execução de projetos de cocriação de valor, ela induz à competição via custo.

A unânime percepção dos entrevistados acerca da inviabilidade dos projetos conjuntos de melhoria (cocriação) sugere a existência de um limite inferior às proposições de Hoyer et al. (2010). Essa possibilidade, caso confirmada, indicará que a viabilidade dos projetos de cocriação de valor é dependente do tipo de demanda de valor requerida pelos clientes. Tal dependência pode determinar que certas demandas não são adequadas à cocriação de valor. Com base nessa constatação, enuncia-se o seguinte achado de pesquisa, válido apenas no contexto das empresas investigadas: a viabilidade da adoção da cocriação de 
valor no setor de serviços de transporte encontra-se limitada pelas especificidades da demanda de valor apresentada pelos clientes.

A extensão de tais achados a outras empresas do setor e a outros setores exige outros métodos de pesquisa, com maior alcance que o método ora empregado.

\section{Conclusões}

Este estudo analisou a possibilidade de desenvolvimento de projetos de cocriação de valor nos serviços de transporte rodoviário de carga. Em um primeiro momento foram analisadas as demandas de valor das empresas que fazem uso desse tipo de serviço. Posteriormente investigaram-se as alternativas para o desenvolvimento de projetos de cocriação na área de transporte de cargas.

A análise dos achados de pesquisa aponta indícios de que a cocriação não é viável nesse tipo de serviço em função de dois limitadores, a saber: a grande oferta de transportadores de carga e as peculiaridades das demandas de valor apresentadas pelos clientes do serviços. Com efeito, a combinação dos referidos fatores parece induzir a uma competição essencialmente focada no quesito preço, condição essa que associada ao grande número de provedores de serviços impede o desenvolvimento de projetos de melhoria conjunta.

Como limitação do estudo tem-se o fato de que todos os achados foram provenientes de uma abordagem qualitativa (estudo de caso), a qual não permite generalização dos achados. Aspectos regionais e culturais não foram igualmente considerados.

\section{Referências}

Aktas, E., \& Ulengin, F. (2005). Outsourcing logistics activities in Turkey. Journal of Enterprise Information Management, 18(3), 316-329. http://dx.doi. org/10.1016/j.trc.2011.02.005

Alamo, J., \& Brinati, M. (2006). Modelagem para localização de hubs no transporte de encomendas expressas. Produção, 16(3), 470-480. http://dx.doi.org/10.1590/ S0103-65132006000300009

Anderson, J., \& Narus, J. (1998). Business marketing: Understand what customers value. Harvard Business Review, 76, 53-65.

Auerbach, C., \& Silverstein, L. (2003). Qualitative Data: an Introduction to Coding and Analysis. New York: New York University Press.

Baines, T., Lightfoot, H., Evans, S., Neely, A., Greenough, R., \& Peppard, J. (2007). State-of-the-art in productservice systems, Proceedings of the Institution of Mechanical Engineers, Part B: Journal of Engineering Manufacture, 221(10), 1543-1552. http://dx.doi. org/10.1243/09544054JEM858
Barry, J., \& Terry, T. S. (2008). Empirical study of relationship value in industrial services. Journal of Business and Industrial Marketing, 23(4), 228-241. http://dx.doi. org/10.1108/08858620810865807

Bolton, R., \& Saxena-lyer, S. (2009). Interactive Services: A Framework, Synthesis and Research Directions. Journal of Interactive Marketing, 23(1), 91-104. http://dx.doi. org/10.1016/j.intmar.2008.11.002

Boyson, S., Corsi, T., Dresner, M., \& Rabinovich, E. (1999). Managing effective third party logistics relationship: what does it take?. Journal of Business Logistics, 20(1), 73-100.

Bryman, A. (2004). Social Research Methods. Oxford: 0xford University Press.

Cassel, C., \& Symon, G. (1990). Qualitative methods in organizational research. London: Sage Publications.

Confederação Nacional de Transportes - CNT. (2011). Transporte de Cargas no Brasil: Ameaças e Oportunidades para o Desenvolvimento do País - Diagnóstico e Plano de Ação. Retrieved from http://www.cnt.org.br/portal/ arquivos/cnt/downloads/coppead_cargas.pdf.

Eisenhardt, K. (1989). Building theories from case study research. Academy of Management Review, 14(4), 532-550.

Evanschitzky, H., Wangenheim, F., \& Woisetschläger, D. (2011). Service \& solution innovation: Overview and research agenda. Industrial Marketing Management, 40(5), 657660.http://dx.doi.org/10.1016/j.indmarman.2011.06.004

Franke, N., Keinz, P., \& Steger, C. (2009). Testing the Value of Customization: When Do Customers Really Prefer Products Tailored to Their Preferences? Journal of Marketing, 73(5), 103-121. http://dx.doi.org/10.1509/ jmkg.73.5.103

Glaser, B., \& Strauss, A. (2006). The Discovery of Grounded Theory: Strategies for Qualitative Research. New York: Sociology Press.

Han, D., \& Yang, H. (2009). Congestion pricing in the absence of demand functions. Transportation Research Part E: Logistics and Transportation Review, 45(1), 159171. http://dx.doi.org/10.1016/j.tre.2008.03.002

Heinonen, K., Strandvik, T., Mickelsson, K., Edvardsson, B., Sundström, E., \& Andersson, P. (2010). A customer-dominant logic of service. Journal of Service Management, 21(4), 531-548. http://dx.doi. org/10.1108/09564231011066088

Helander, A., \& Moller, K. (2008). How to Become Solution Provider: System Supplier's Strategic Tools. Journal of Business-to-Business Marketing, 15(3), 247-289. http:// dx.doi.org/10.1080/15470620802059265

Hill, C., Thompson, B., \& Williams, E. (1997). A guide to conducting consensual qualitative research. Counseling Psychologist, 25(5), 517-572. http://dx.doi. org/10.1177/0011000097254001

Hoyer, W., Chandy, R., Dorotic, M., Krafft, M., \& Singh, S. (2010). Consumer Cocreation in New Product Development. Journal of Service Research, 13(3), 283296. http://dx.doi.org/10.1177/1094670510375604

Hsu, C., Liao, P., Yang, L., \& Chen, Y. (2005). Hightechnology firms' perception and demand for air cargo logistics services, Journal of the Eastern Asia Society for Transportation Studies, 6(10), 2868-2880.

King, N. (2004). Using interviews in qualitative research. In C. Cassel, \& G. Symon (Org.), Essential Guide to 
Qualitative Methods in Organizational Research (pp. 1122). Thousand Oaks: Sage.

Kristensson, P., Gustafsson, A., \& Archer, T. (2004). Harnessing the creativity among users. Journal of Product Innovation Management, 21(1), 4-15. http:// dx.doi.org/10.1111/j.0737-6782.2004.00050.x

Kristensson, P., Gustafsson, A., \& Archer, T. (2008). Key strategies for the successful involvement of customers in the co-creation of new technologybased services. International Journal of Service Industry Management, 19(4), 474-491. http://dx.doi. org/10.1108/09564230810891914

Lin, C., Lin, D., \& Young, M. (2009). Price planning for time-definite less-than-truckload freight services. Transportation Research Part E: Logistics and Transportation Review, 45(4), 525-537. http://dx.doi. $\operatorname{org} / 10.1016 / j$.tre.2008.12.004

Lindgreen, A., \& Wynstra, F. (2005). Value in business markets: What do we know? Where are we going? Industrial Marketing Management, 34(7), 732-748. http://dx.doi.org/10.1016/j.indmarman.2005.01.001

Lu, C. (2004). An evaluation of logistics services' requirements of international distribution centers in Taiwan. Transportation Journal, 34(1), 53-66.

Lusch, R. F., Vargo, S. L., \&t O’Brien, M. (2007). Competing through service: lnsights from service-dominant logic. Journal of Retailing, 83(1), 5-18. http://dx.doi. org/10.1016/j.jretai.2006.10.002

Macdonald, E., Wilson, H., Martinez, V., \& Toossi, A. (2011). Assessing value-in-use: a conceptual framework and exploratory study. Industrial Marketing Management, 4O(5), 671-682. http://dx.doi.org/10.1016/j. indmarman.2011.05.006

Maier, G., Bergman, E., \& Lehner, P. (2002). Modelling preferences and stability among transport alternatives. Transportation Research Part E, 38(3), 319-334. http:// dx.doi.org/10.1016/S1366-5545(02)00015-7

Mathwick, C., Wiertz, C., \& Ruyter, K. (2007). Social Capital Production in a Virtual P3 Community. Journal of Consumer Research, 34(6), 832-849. http://dx.doi. $\operatorname{org} / 10.1086 / 523291$

Menon, M., McGinnis, M., \& Ackerman, K. (1998). Selection criteria for providers of third-party logistics services: an exploratory study. Journal of Business Logistics, 19(2), 121-137.

Miles, M., \& Huberman, M. (1994). A Qualitative Data Analysis: an Expanded Sourcebook. Thousand Oaks: Sage.

Moller, K. (2006). Role of competencies in creating customer value: A value-creation logic. Industrial Marketing Management, 35(9), 913-924. http://dx.doi. org/10.1016/j.indmarman.2006.04.005

Neely, A. (2008). Exploring the financial consequences of the servitization of manufacturing. Operations Management Review, 1(2), 103-118.

Ngo, L., \& O'Cass, A. (2009). Creating value offerings via operant resource-based capabilities. Industrial Marketing Management, 38(1), 45-59. http://dx.doi.org/10.1016/j. indmarman.2007.11.002

Norojono, 0., \& Young, W. (2003). A stated preference freight mode choice model. Transportation Planning and Technology, 26(3), 195-212.
Ostrom, A., Bitner, M., Brown, S., Burkhard, K., Goul, M., \& Smith-Daniels, V. (2010). Moving forward and making a difference: Research priorities for the science of service. Journal of Service Research, 13(1), 4-36. http://dx.doi. org/10.1177/1094670509357611

Özkaya, E.; Keskinocak, P., Joseph, V., \& Weight, R. (2010). Estimating and benchmarking Less-than-Truckload market rates. Transportation Research Part E: Logistics and Transportation Review, 46(5), 667-682. http:// dx.doi.org/10.1016/j.tre.2009.09.004

Payne, A., Storbacka, K., \& Frow, P. (2008). Managing the cocreation of value. Journal of the Academy of Marketing Science, 36(1), 83-96. http://dx.doi.org/10.1007/ s11747-007-0070-0

Pereira, G., Sellitto, M., Borchardt, M., \& Geiger, A. (2011). Procurement cost reduction for customized non-critical items in an automotive supply chain: An action research project. Industrial Marketing Management, 40(1), 28-35. http://dx.doi.org/10.1016/j.indmarman.2010.09.007

Prahalad, C., \& Ramaswamy, V. (2004). Co-creation experiences: The next practice in value creation. Journal of Interactive Marketing, 18(3), 5-14. http://dx.doi. org/10.1002/dir.20015

Rosa, E., Sellitto, M., \& Mendes, L. (2006). Avaliação multicriterial de desempenho e separação em aglomerados de fornecedores críticos de uma manufatura OKP. Produção, 16(3), 413-428. http://dx.doi.org/10.1590/ S0103-65132009000100005

Smith, L. D., Campbell, J. F., Mundy, R. (2007). Modeling net rates for expedited freight services. Transportation Research Part E: Logistics and Transportation Review, 43(2), 192-207. http://dx.doi.org/10.1016/j. tre.2005.11.001

Strauss, A., \& Corbin, J. (1990). Basics of Qualitative Research: Grounded Theory Procedures and Techniques. Newbury Park: SAGE.

Tsai, M., Wen, C., \& Chen, C. (2007). Demand choices of hightechnology industry for logistics service provides - an empirical case of an offshore science park in Taiwan. Industrial Marketing Management, 36(6), 617-626. http://dx.doi.org/10.1016/j.indmarman.2006.03.002

Ulaga, W. (2003). Capturing value creation in business relationships: A customer perspective. Industrial Marketing Management, 32(6), 677-693. http://dx.doi. org/10.1016/j.indmarman.2003.06.008

Ulaga, W., \& Chacour, S. (2001). Measuring customerperceived value in business markets: a prerequisite for marketing strategy development and implementation. Industrial Marketing Management, 30(5), 525-540. http://dx.doi.org/10.1016/S0019-8501(99)00122-4

Ulaga, W., \& Eggert, A. (2006). Relationship value and relationship quality. Broadening the nomological network of business-to-business relationships. European Journal of Marketing, 40(3), 311-327. http://dx.doi. org/10.1108/03090560610648075

Van Doorn, J., Lemon, K. N., Mittal, V., Nass, S., Pick, D., Pirner, P., \& Verhoef, P. C. (2010). Customer engagement behavior: Theoretical foundations and research directions. Journal of Service Research, 13(3), 253-266. http://dx.doi.org/10.1177/1094670510375599

Vargo, S., \& Lusch, R. (2004). Evolving to a new dominant logic for marketing. Journal of Marketing, 68(1), 1-17. http://dx.doi.org/10.1509/jmkg.68.1.1.24036 
Vargo, S., \& Lusch, R. (2008). Service-dominant logic: Continuing the evolution. Journal of the Academy of Marketing Science, 36(1), 1-10. http://dx.doi. org/10.1007/s11747-007-0069-6

Vargo, S., Maglio, P., \& Akaka, M. (2008). On value and value co-creation: A service systems and service logic perspective. European Management Journal, 26(2), 145152. http://dx.doi.org/10.1016/j.emj.2008.04.003

Wanke, P. (2012). Fatores de satisfação com o uso de autônomos no transporte rodoviário de cargas. Produção, 22(3), 584-595. http://dx.doi.org/10.1590/ S0103-65132012005000046

Wen, C., Tsai, M., \& Lin, C. (2011). Classification and competition analysis of air cargo logistics providers: The case of Taiwan's high-technology industry. Journal of Air Transport Management, 17(2), 106-109. http://dx.doi. $\operatorname{org} / 10.1016 /$ j.jairtraman.2010.10.012
Woodruff, R., \& Flint, D. (2006). Marketing's servicedominant logic and customer value. In R. Lusch, \& S. Vargo (Orgs.), The service-dominant logic of marketing: dialog, debate, and directions. New York: Sharpe.

Yang, H., Xu, W., \& Heydecker, B. (2010). Bounding the efficiency of road pricing. Transportation Research Part E: Logistics and Transportation Review, 46(1), 90-108. http://dx.doi.org/10.1016/j.tre.2009.05.007

Yin, R. (2003). Case Study Research: Design and Methods. Thousand Oaks: Sage.

\section{Agradecimentos}

Parte da pesquisa foi financiada pelo CNPq e pela FAPERGS. Agradecemos a Mateus Bottini Maciel pelo auxílio na revisão bibliográfica.

\title{
Co-creation of value in road cargo transport: a case study
}

\begin{abstract}
This paper investigates whether transport service providers can apply the co-creation of value. The presented multiple case study focused on the shippers and logistics providers. Value co-creation constructs extracted from the literature provided the theoretical background for the research. The following topics were investigated: the buyers' value demands, the criteria used by the buyers to evaluate the value offered by the service providers and the possibility of value co-creation between buyers and sellers. The findings uncovered two main barriers to the value co-creation in the transport services, namely a large number of service providers (which restricts the competition to the cost of the services) and the customers' demands. The combination of these elements suggests the impracticality of adopting co-creation in the context of road cargo transport. Such findings also may indicate the existence of a lower limit to the value approach in the service industry (e.g., in the transport services).
\end{abstract}

Keywords

Value co-creation. Service. Transport. Value. 